\title{
Clothing and Teacher Credibility: An Application of Expectancy Violations Theory
}

\author{
Norah E. Dunbar ${ }^{1}$ and Chris Segrin ${ }^{2}$ \\ ${ }^{1}$ Department of Communication, The University of Oklahoma, Norman, OK 73019-2081, USA \\ ${ }^{2}$ Department of Communication, The University of Arizona, Tucson, AZ 85721, USA \\ Correspondence should be addressed to Norah E. Dunbar, ndunbar@ou.edu
}

Received 6 December 2011; Accepted 26 December 2011

Academic Editors: K. Y. Kuo, S. Lunsford, and G. Sideridis

Copyright (C) 2012 N. E. Dunbar and C. Segrin. This is an open access article distributed under the Creative Commons Attribution License, which permits unrestricted use, distribution, and reproduction in any medium, provided the original work is properly cited.

\begin{abstract}
Clothing is an important aspect of communication that can influence the perceptions of wearers' credibility and attractiveness as well as a variety of other judgments. In the classroom, these perceptions are made by students about teachers and are a function of the type of behavior expected from their teachers. This paper argues that we have expectations for appropriate and inappropriate attire. Burgoon's expectancy violations theory was applied to the study of clothing and the credibility of instructors in college classes. Two instructors gave lectures in undergraduate college classes and violated or adhered to the students' expectations for appropriate attire and acted in a highly rewarding or less rewarding manner. The results do not support the U-shaped pattern predicted by expectancy violations theory, but rather, the results suggest that teachers should strive for a moderately formal clothing style. This result is qualified by the finding that students appeared to have attended to their instructors' clothing less under conditions of high reward than in the low-reward conditions. This suggests that teachers' clothing will be a less consequential determinant of the impression that their students form when the teachers are otherwise perceived as having a high instrumental value in and of themselves.
\end{abstract}

\section{Introduction}

Clothing is an area of visual communication that is of great interest to scholars and the lay public alike. There are laws and ordinances that govern it and strict social norms for its appropriateness. Clothing is constantly used to measure and display status and a host of other social variables. Virtually everyone has expectations for what types of dress will be worn in specific social contexts and violations of those norms may elicit a range of responses from onlookers. In addition to societal-level norms, we also have expectations for the behavior of particular individuals who we know based on our regularly occurring interactions with them. One important context in which these expectations clearly play a part is in the classroom. When building a rapport with students, instructors are often aware of the impression they make on their students with their appearance. Many studies have been conducted to shed light on the impact of instructor attire on student perceptions but no studies have taken the character of the individual instructor into account. Expectancy Violations Theory (EVT) explains how both societal and individual expectations contribute to reactions to those whose behavior noticeably deviates from expectations [1-3]. Given the importance of clothing for making judgments about others in everyday interaction, EVT appears to hold considerable promise for predicting the impact of instructor clothing practices on the impressions of students.

\section{Expectancy Violations Theory}

According to Burgoon's research [1-6], EVT frames interpersonal communication patterns and their outcomes within the context of expectancies and violations of those expectations. Expectancies are enduring patterns of anticipated behavior for a particular individual that are appropriate, desired, or preferred. Expectancies can take a variety of forms. For example, when walking through a crosswalk, we expect motorists to stop and wait, and we trust that they will do so. When we go to the dentist, fly on an airplane, 
or take a college course, we expect to deal with people who can perform their jobs competently [7]. Violations of expectancies occur when actions are sufficiently discrepant from the expectancy to be noticeable. Deviant or unexpected behaviors, by virtue of their novelty, can draw attention to the communicator and increase the information processing engaged in by the receiver. For example, if an instructor comes to class wearing a new dress shirt, students are not likely to notice it because it is not sufficiently discrepant from the norm, but if an instructor arrives to teach a class wearing only a t-shirt and shorts, we would certainly notice it because, as EVT suggests, expectancy violations catch our attention and heighten our awareness of the situation [7].

One key assumption of EVT is that communicators have characteristics which have valences attached to them. Suppose a single woman is sitting on a bus and a man sitting across from her is staring at her, thus violating her expectations of eye contact norms. How should she react? This will depend greatly on how she perceives the person committing the expectancy violation. If he is professionally dressed and attractive, she might think he is flirting with her and react positively by returning his stare or smiling at him. If he is shabbily dressed and unattractive, she might assume his stare is threatening and react negatively by averting his gaze or changing seats. EVT assumes that although individual communicators have many characteristics, the communicator reward level refers to whether the communicator, on balance, is deemed rewarding or not and whether or not interactions with the communicator are desired. We evaluate all communicators on a positive to negative continuum according to their apparent "reward value" for us. Communicators who have a high reward level are those who provide more positively valued messages than negatively valued messages. Conversely, communicators who have a low reward level are those who generally provide more negatively valued messages than positively valued messages. Someone who is physically attractive, has a great sense of humor, has high status, can help us attain our goals, or gives us positive feedback, or instance, should be more positively regarded than someone who is physically repulsive, lacks a sense of humor, is of lower status, cannot help us attain goals, or who gives us negative feedback [8]. Heightened awareness of the communicator, caused by expectancy violations, can exaggerate the value of the communicator. When this unexpected behavior is attributed to a rewarding communicator, receivers tend to be more charitable than when unexpected behavior is committed by less rewarding communicators. Thus, highly rewarding communicators are given more "slack" than less rewarding communicators.

The communicator reward level is not the only information available to the person who is interpreting the behavior of others. EVT recognizes that both positively and negatively regarded communicators may commit expectancy violations and that those behaviors have valences attached to them. The violation valence refers to the interpretation about the behavior made by the person observing the behavior, whether positive or negative. An example may clarify this point. Suppose that a student is required to give a speech in her public speaking class. The speech teacher is someone she likes and admires (has high communicator reward) and so she expects positive feedback from the teacher on her speech. If the teacher praises her work and gives her constructive suggestions for improvement, her expectations have been confirmed. If the teacher criticizes her work, saying it is the worst speech she or he has ever heard, thus embarrassing the student in front of the whole class, EVT would call this a negative violation. If the teacher praises her speech glowingly in front of the entire class, saying it is a great example for them to follow, the teacher has committed what EVT would call a positive violation. Thus, communicators with both high and low reward may commit positive or negative expectancy violations, so one must take into account both the behavior itself and the communicator who enacts the behavior when deciding how to interpret a certain function.

When these two variables, the communicator reward level and the violation valence, are combined, EVT makes specific predictions about how their behaviors will be interpreted. Specifically, EVT predicts that positive violations will cause more positive outcomes than confirming behavior and negative violations will produce more negative outcomes than confirmations. Thus, for highly rewarding communicators, violations of expectancies can help to draw attention to the behavior and engender more positive interpretations of the behavior, creating an inverted U-shaped curve with both positive and negative expectancy violations rated more favorably than expectancy confirmations. Less rewarding communicators should avoid expectancy violations, however, because when they draw attention to the communicator, they serve to produce negative evaluations of the behavior, thus creating a U-shaped curve with expectancy conformations rated more favorably than either positive or negative expectancy violations. Many of Burgoon's experiments have confirmed this relationship. For example, in a series of field experiments, Burgoon and Aho [9] provide evidence that rewarding communicators create favorable outcomes by violating, rather than confirming expectations while nonrewarding communicators usually create the most favorable outcomes by confirming rather than violating space expectations.

\section{Instructor Clothing as Communication}

Clothing behavior is an area for obvious application of EVT given that we hold expectations for what appropriate attire is and what certain types of dress mean when they violate these social norms. There is little doubt that style of dress influences the attributions made about the wearer; the empirical evidence for the impact of clothing on impression management abounds. For example, both male and female models' intelligence was judged to be highest when dressed formally [10]. Many studies have shown that the success of compliance-gaining attempts are affected by the clothing worn by the source of the message with formal or highstatus attire resulting in more successful influence attempts [11-15]. Bushman [16, 17] and Bickman [18] found that study participants dressed as authority figures, wearing the 
uniforms of fire fighters or security guards, were able to gain compliance from targets even when their request was not related to their realm of authority. A meta-analysis of nonverbal behavior and compliance gaining indicates that sources wearing more formal and higher-status clothing are more successful at gaining compliance in a variety of contexts [19].

Although there are no studies of instructor attire that directly test the expectancies of students for their teachers, there are a plethora of studies that examine the desirability of various clothing types in an instructional setting. This section will first review those studies that demonstrate the influence clothing has on perceptions of instructors so that the influence of expectancy violations can be discussed later. For example, many studies have shown that teachers can gain more credibility from their students when they dress more formally. School administrators feel that formal clothing is more appropriate for classroom teachers than informal clothing [20]. Bassett [21] found that high-status dress (suit and tie for males, a dress and heels for females) was rated as significantly more credible than low-status dress (jeans and work shirt for males, inexpensive blouse and shoes for females). Professional attire of instructors can even affect the perceptions students have of their educational experience after graduation [22].

Student ratings of instruction are also higher for teaching assistants who are perceived to dress more professionally [23]. Teaching assistants wearing formal clothing received a higher score on credibility, intelligence, and preparation than those wearing semiformal or informal clothing [24]. Informal clothing is not always negative, though, because instructors dressed in informal clothing style (jeans and a sweater) were rated as most approachable and flexible, yet elicited ratings of least respect [25]. According to Butler and Roesel [25], teachers in jeans are viewed as fun, approachable, not especially knowledgeable, commanding limited respect, not looking like a teacher, but generally the style students prefer overall. In contrast, the suited teacher was seen as unapproachable, not especially fun, but someone who possessed the image of a teacher. Similarly, Davis [26] found that formality was negatively associated with friendliness, sympathy, clarity of communication, enthusiasm, and flexibility but positively associated with knowledge. A moderate clothing style is formal enough to command respect, yet not so formal as to discourage contact among college students $[27,28]$.

Similarly, in another study of college students' attributions, Sweat and Zentner [29] found that teachers wearing dramatic styles (bold or severe design lines) were seen as unconventional, approachable, sophisticated, and dominant. Those wearing natural styles (informal, casual, and comfortable, with minimal ornamentation) were viewed as conventional, somewhat approachable and unsophisticated, and slightly dominant. Teachers wearing romantic styles (feminine with gently curved lines) were seen as approachable, unconventional, sophisticated, and submissive while those wearing classic styles (simple, conservative, and tailored) were seen as very conventional, sophisticated, and dominant as well as somewhat standoffish.
Lukavsky, et al. [27] suggest that a moderate style which encourages contact but also fosters credibility and respect is the ideal. This suggests that for many students, what is most expected and desired is a moderate degree of formality in the attire of their instructors, but no studies have taken into account the reward value of the instructor. Based on the propositions of EVT, when a behavior is enacted by a positively valenced communicator (i.e., someone with high reward value), deviation from expectation will be associated with more positive communication outcomes, relative to behaviors that meet expectation. On the other hand, for a negatively valenced communicator (i.e., someone with low reward value), any deviations from the norm will be evaluated negatively. Prior research on EVT suggests that these patterns will hold for attitudinal or evaluative outcomes such as ratings of source credibility and attractiveness as well as cognitive outcomes such as attention to message or information processing $[1,2]$. We therefore developed hypotheses from EVT that include these two classes of communication outcomes. In terms of evaluative outcomes, we hypothesized the following.

H1: For high reward value teachers, the relationship between deviation from expectations and evaluations of the teacher is curvilinear such that either a positive or negative deviation will produce the most positive evaluations of credibility and attraction and the most recall of message information than behaviors that meet expectations.

$\mathrm{H} 2$ : For low reward value teachers, the relationship between deviation from expectations and evaluations of the teacher is curvilinear such that either positive or negative deviations will produce the most negative evaluations of credibility and attraction and less recall of message information than behaviors that meet expectations.

\section{Overview of Present Experiment}

Many studies of clothing effects use photographs as the stimulus materials, often with the heads removed in order to eliminate any bias. Butler and Roesel [30] acknowledge that this has the effect of ensuring the perceiver's attention to clothing. However, this method comes at the cost of mundane realism. Clothing messages are complex and are combined with a host of other nonverbal and verbal messages [31]. In a realistic setting, additional stimuli may dilute the strength of the clothing cue but would more closely approximate the judgments made of teachers while lecturing in a classroom [30]. As a result, a method utilizing actual teachers similar to that used by Morris et al. [32] and Gorham et al. [33] in two of their "fashion in the classroom" studies was used. In the present experiment, styles of clothing that were less formal than expected, expectedly formal, and more formal than expected were selected based on extensive pilot-testing. Actual teachers then wore these exact outfits while giving a guest lecture in a college class, under conditions of high or low reward value to the students. 
TABle 1: Means and standard deviations for appropriateness/ expectation of apparel presented in the pretest.

\begin{tabular}{lccc}
\hline & \multicolumn{3}{c}{ Formality of clothing } \\
Wearer & Less than expected & As expected & More than expected \\
\hline Female & $1.98^{*}(.90)$ & $4.29(.66)$ & $3.95^{*}(.81)$ \\
Male & $1.66^{*}(.92)$ & $4.29(.64)$ & $3.25^{*}(1.15)$ \\
\hline
\end{tabular}

Note: standard deviations are in parentheses. Significant differences between males and females are noted with an asterisk $(P<.05)$.

\section{Method}

5.1. Participants. Participants were 240 students enrolled in a multisection course on business communication at a large southwestern university. The participants' average age was $21.86(S D=3.62)$ with $65 \%$ males and $35 \%$ females. Participants' racial backgrounds were as follows: $1 \%$ American Indian or Alaskan Native, 10\% Asian or Pacific Islander, 1\% Black, 9\% Hispanic, 76\% White, and 3\% other. The self-rated socioeconomic status of participants' families of origin was 12\% "upper class," $46 \%$ "upper-middle class," $36 \%$ "middle class," 5\% "lower-middle class," and 2\% "lower class."

5.2. Pilot Test. A pilot test was conducted in order to estimate the expectations of undergraduate students for "moderate" attire of their instructors. Participants for the pilot test were 208 students in either one of 8 sections of the class mentioned, or 2 sections of a comparable class. Students who participated in the pilot test were not involved in the actual experiment. Participants in the pilot test viewed 15 slides of the confederates, who were actually college instructors who were part of the experiment, in "formal," "moderate," or "casual" clothing presented in random order.

The stimulus included multiple instantiations of each level of formality. The pictures were cropped so that the model and his or her clothing were only evident from the neck down. Subjects saw each slide for 25 seconds and were asked to rate how appropriate, reasonable, expected, usual, and consistent the attire was using a semantic differential scale while they viewed the slide. Alpha reliabilities for this scale ranged from .76 to .89 for the different clothing conditions, with and average alpha of .83. This combined index was used as a dependent measure to select different clothing examples for use in the actual study. Three different sets of apparel (formal, moderate, and casual) were selected for a male style of dress, and a corresponding set of three outfits were selected for a female style of dress based upon results of the pilot test. These 6 clothing examples were selected by virtue of (1) being significantly different from each other based on a one-way ANOVA with formality as the independent variable for males, and a similar ANOVA for the female style and (2) the lack of a significant difference in the ratings of the male and female style at the same level of formality (i.e, the female casual could not be significantly different from the male casual). Means, standard deviations, and results of these analyses appear in Table 1 and the actual apparel appears in Figure 1.
As evident from Table 1, the three clothing conditions were significantly different from each other for both the male and female models however, there were some significant differences in violations of expectations for the male and female model at the same level of formality (although the pilot test indicated that the male and female confederate were significantly different in some cases, this was taken as a product of their clothing (the female was dressed more casually than the male in the informal condition and the male was dressed more formally than the female in the formal condition) we were limited by their wardrobes, and thus these differences should not be taken as concrete sex differences for the analyses of the experimental data, the two confederates were combined as such, these two confederates should not be seen representative of all males and all females).

5.3. Procedure. For the main experiment, one male and one female graduate teaching assistant served as confederates in the study. These confederates were the same instructors with the same outfits as those who appeared in the pilot test. They were each in their late 20s, of similar build, attractiveness, and ethnicity. The confederates were given a 15-minute guest lecture that they presented to 12 discussion sections of a business communication class during their regularly scheduled class meetings. The sizes of each group are presented in Table 2.

Each confederate gave the guest lecture 6 times, three times in the positive reward and three times in the negative reward condition while wearing formal, moderate, and casual attire. The formal condition consisted of a dark suit and conservative tie for the male and a dark suit and high-heels for the female. The moderate clothing condition consisted of a collared dark golf shirt and khaki slacks for the male and a long-sleeve dark blouse and tan slacks for the female. The casual condition consisted of a plain t-shirt, shorts, and running shoes for the male and a flannel shirt, sweat pants, and sandals with socks for the female. The confederates were trained not to stray from their script and to use identical visual aids and nonverbal cues in order to assure comparability across sections, but care was taken to ensure the practiced speech sounded natural.

Positive and negative valance of the instructors was manipulated at the beginning of the confederates' guest lecture. In the positive reward condition, the confederate presented an overhead transparency with some free exam questions and the subjects were given time to copy them down. The confederate told the subjects:

Your professor has asked me to write a couple of exam questions for your final exam. I think the best way to start off this lecture is by giving you those questions. I think it will help you focus on the lecture a little better since you'll know what to be watching for. These three exam questions will be on your finalwrite the answers down, they are freebees!

In the negative reward condition, the confederate presented a list of 45 possible exam topics on an overhead 

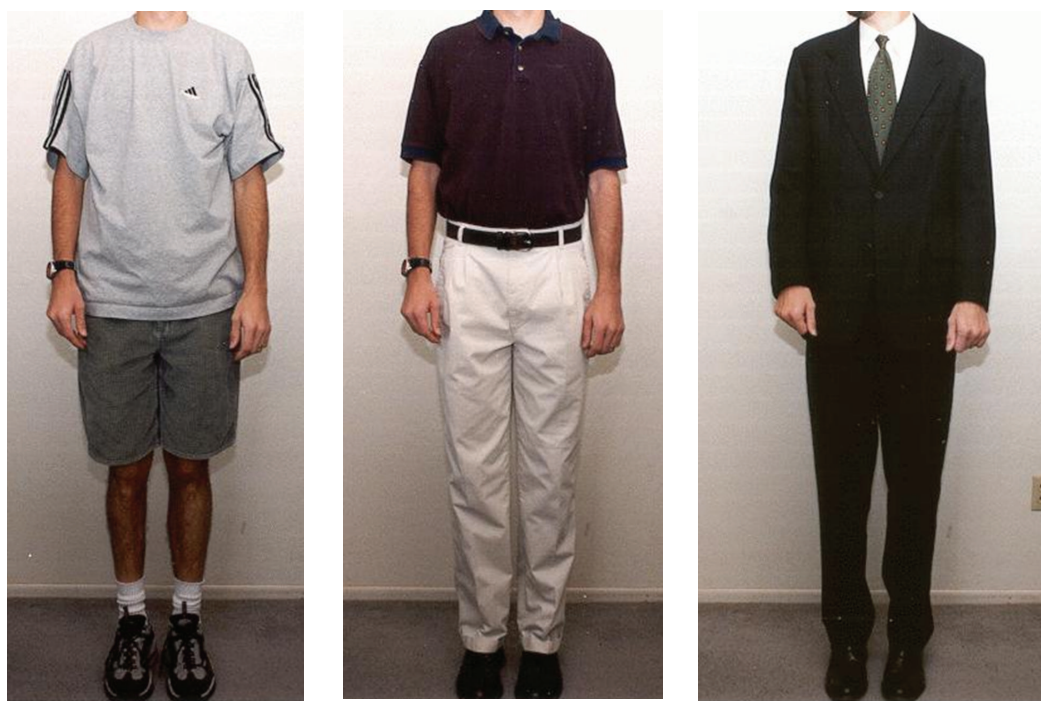

(a) Male clothing selected from pilot test
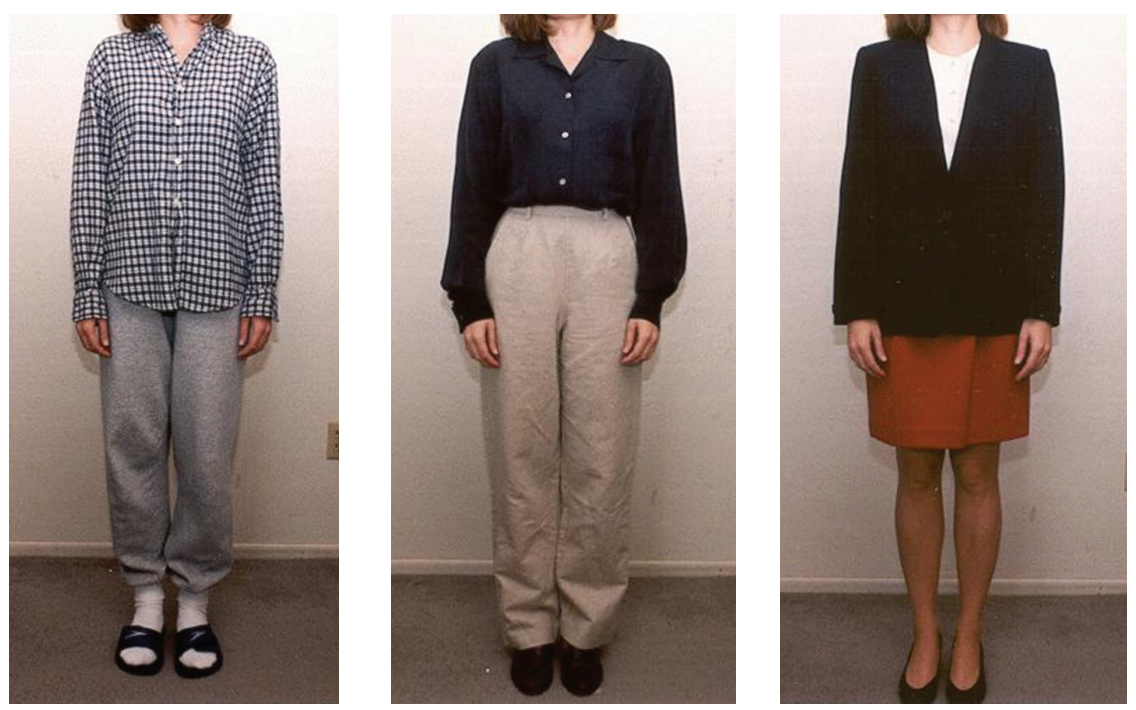

(b) Female clothing selected from pilot test

FIgURE 1: Clothing styles worn by confederates in the experiment.

TABLE 2: Cell sizes and means and standard deviations for all dependent measures.

\begin{tabular}{|c|c|c|c|c|c|c|c|c|c|c|c|c|c|c|c|c|c|}
\hline \multirow[b]{2}{*}{ Sex } & \multirow[b]{2}{*}{ Reward } & \multirow[b]{2}{*}{ Formality } & \multirow[b]{2}{*}{$N$} & \multicolumn{2}{|c|}{ Competence } & \multicolumn{2}{|c|}{ Character } & \multicolumn{2}{|c|}{ Caring } & \multicolumn{2}{|c|}{ Soc. Attrac. } & \multicolumn{2}{|c|}{ Phys. Attrac. } & \multicolumn{2}{|c|}{ Homophily } & \multicolumn{2}{|c|}{ Recall } \\
\hline & & & & $M$ & $S D$ & $M$ & $S D$ & $M$ & $S D$ & $M$ & $S D$ & $M$ & $S D$ & $M$ & $S D$ & $M$ & $S D$ \\
\hline \multirow{6}{*}{ Male } & \multirow{3}{*}{ High } & Casual & 22 & 2.05 & .60 & 1.86 & .64 & 2.47 & .51 & 4.66 & 1.07 & 4.03 & .69 & 4.08 & .73 & 2.80 & 1.06 \\
\hline & & Moderate & 18 & 2.09 & 1.02 & 2.06 & 1.01 & 2.80 & .76 & 4.23 & 1.26 & 4.22 & 1.22 & 4.04 & 1.01 & 2.72 & 1.07 \\
\hline & & Formal & 21 & 2.09 & .63 & 2.33 & .56 & 2.83 & .59 & 4.56 & .91 & 3.91 & 1.13 & 3.84 & .89 & 3.37 & .50 \\
\hline & \multirow{3}{*}{ Low } & Casual & 21 & 2.17 & .51 & 2.12 & .50 & 2.75 & .43 & 4.53 & .78 & 3.90 & .95 & 4.06 & .69 & 3.10 & .79 \\
\hline & & Moderate & 12 & 1.78 & .47 & 2.01 & .43 & 2.56 & .76 & 4.80 & 1.08 & 4.52 & 1.39 & 4.86 & 1.20 & 3.42 & .67 \\
\hline & & Formal & 18 & 2.06 & .59 & 2.56 & .93 & 3.26 & .72 & 3.82 & 1.05 & 3.51 & .99 & 3.57 & .75 & 2.78 & .81 \\
\hline \multirow{6}{*}{ Female } & \multirow{3}{*}{ High } & Casual & 22 & 2.38 & .63 & 2.43 & .65 & 3.11 & .77 & 4.20 & .97 & 4.04 & 1.18 & 4.02 & .45 & 2.68 & .95 \\
\hline & & Moderate & 22 & 2.20 & .56 & 1.86 & .45 & 2.78 & .57 & 4.39 & .83 & 4.43 & .98 & 3.85 & .85 & 3.05 & .95 \\
\hline & & Formal & 25 & 2.42 & .60 & 2.41 & .65 & 3.05 & .73 & 4.18 & .83 & 4.59 & 1.09 & 3.83 & .78 & 2.33 & .87 \\
\hline & \multirow{3}{*}{ Low } & Casual & 20 & 2.43 & .46 & 2.47 & .54 & 2.94 & .58 & 3.97 & .84 & 3.49 & .94 & 3.83 & .57 & 2.32 & 1.06 \\
\hline & & Moderate & 19 & 2.40 & .67 & 2.07 & .64 & 2.86 & .57 & 4.40 & .77 & 4.58 & 1.24 & 3.70 & 1.04 & 3.56 & .71 \\
\hline & & Formal & 20 & 3.08 & .65 & 3.17 & .59 & 3.44 & .60 & 4.03 & .97 & 4.34 & 1.68 & 3.78 & .96 & 2.95 & 1.13 \\
\hline
\end{tabular}


transparency and did not give the subjects enough time to write them down. The confederate said:

Your professor has asked me to write a couple of exam questions for your final exam. I think the best way to start off this lecture is by quickly showing you a list of topics that I could use to make up those exam questions. You do not need to write them all down because I will be discussing all of these things in the next 15 minutes.

After the guest lecture, the confederate gave the subjects the posttest questionnaire and left the room. The subjects' regular class instructors (also graduate students) collected the surveys and returned them to the experimenters. Although there are a variety of ways in which a communicator's positive and negative reward value could be manipulated, the nature of the confederate's contact with the subjects and the motivations and goals of the subjects put constraints on potential operationalizations of reward value. We sought to develop a manipulation that would be unambiguous, easily implemented in a classroom setting, and equally meaningful to all audience members, while still being realistic in the context of an educational setting. By having the guest lecturer either give students exam questions and answers or just a long list of potential exam question topics, subjects would either immediately recognize the value of the guest lecturer or dismiss the information about exam questions as useless, if not become downright agitated with the guest lecturer's flippancy. In so doing, the reward value manipulation was designed to create a sense of utility and helpfulness (or lack thereof) in the guest lecturer.

\subsection{Dependent Measures}

5.4.1. Credibility. Perceptions of the confederates' credibility were measured using the 6-item competence $(\alpha=.83)$ and the 6-item character $(\alpha=.84)$ subscales from McCroskey [34] credibility instrument. As an additional measure of credibility, participants completed Teven and McCroskey's [35] 9-item perceived caring measure $(\alpha=.89)$. All items were measured on a 5-point semantic differential differential scale. The competence subscale included items with endpoints such as "reliable/unreliable," "informed/uninformed," and "qualified/unqualified." Character was measured with items such as "honest/dishonest," "pleasant/unpleasant," and "friendly/unfriendly." The caring measure included items such as "cares about me/does not care about me," "has my interests at heart/does not have my interests at heart," and "self-centered/not self-centered."

5.4.2. Attractiveness and Similarity. Attractiveness was measured using a 7-point Likert-type scale using the 5-item physical attraction $(\alpha=.80)$ and 5 -item social attraction $(\alpha=.68)$ subscales of the interpersonal attraction measure [36]. The physical attraction items included "I think he or she is quite handsome or pretty" and "I find him or her attractive physically." The social attraction dimension included items such as "I think he or she could be a friend of mine" and "I would like to have a friendly chat with him or her." The perceived homophily scale [37] was used to measure perceptions of similarity to the target and included items measured on a 7-point semantic differential scale such as "does not think like me/thinks like me" and "similar to me/different than me." Although originally designed with 4-item attitudinal and 4-item background subscales, these were combined into a 8-item general homophily index $(\alpha=$ .82) due to the low reliability of the background subscale. Attractiveness is a common dependent variable in socialpsychological research and was measured by the majority of our literature cited previously. In order to keep our study consistent with past research, we included attractiveness in our study. Attractiveness and similarity are treated as similar dependent variables in the analyses here because of the link documented by many theorists between the two constructs $[38,39]$.

5.4.3. Recall. Participants' recall of the lecture material was measured using four multiple-choice questions based on information presented in the guest lecture, producing a scale that ranged from 0-4 depending on the number of answers the subjects correctly recalled.

\section{Results}

Hypothesis 1 predicted that high-reward teachers would be rated most positively under conditions of deviations from expectation (either more or less formal) compared to those who meet expectations. Hypothesis 2 predicted that lowreward teachers would be rated most positively when they meet participants' expectations for clothing formality, and that they would experience comparatively lower ratings when their clothing deviates (either more or less formal) from expectation. These hypotheses were evaluated with a series of 2 (reward value: high, low) by 3 (clothing formality: formal, moderate, casual) MANOVAs that treated the credibility ratings (competence, character, and caring) attractiveness ratings (social attractiveness, physical attractiveness, and homophily) and recall of the lecture as dependent measures. Although sex was not a theoretical variable of interest, we conducted the analyses initially with the sex of the respondent as a covariate but, contrary to the findings of others like Lightstone et al. [28], sex of the respondent did not have an appreciable effect on the results. There was only two out of seven variables, social attractiveness, $F(1,225)=$ 5.22, $P=.02, \eta^{2}=.02$ and message recall, $F(1,225)=$ 11.26, $P<.01, \eta^{2}=.05$ for which there was a significant difference (females saw the confederates as more socially attractive but males had greater recall of the lectures overall) and sex did not interact with any of the study variables (reward, formality, or reward X formality) thus, sex was not included as a covariate for any of the analyses reported. The means and standard deviations for all seven dependent variables can be found in Table 2 .

Results of this analysis for the credibility ratings, found in Table 3, revealed a significant multivariate main effect for confederate reward value, and for clothing formality. However, there was no reward by clothing formality interaction. 
TABLE 3: Multivariate analysis of variance for credibility ratings.

\begin{tabular}{lll}
\hline $\begin{array}{l}\text { Independent } \\
\text { variable }\end{array}$ & Multivariate effect & Univariate effects \\
\hline Reward & Wilks's $\Lambda=0.97, F(3,230)=2.75, P=.044$ & Competence $F(1,232)=3.20, P=.075, \eta^{2}=.01$ \\
& & $\begin{array}{l}\text { Character } F(1,232)=8.29, P=.004, \eta^{2}=.03 \\
\text { Caring } F(1,232)=2.71, P=.101, \eta^{2}=.01\end{array}$ \\
& Wilks's $\Lambda=0.86, F(6,460)=6.05, P<.001$ & Competence $F(2,232)=3.53, P=.031, \eta^{2}=.03$ \\
Formality & & Character $F(1,232)=16.94, P<.001, \eta^{2}=.12$ \\
& & Caring $F(1,232)=8.08, P<.001, \eta^{2}=.06$ \\
$\begin{array}{l}\text { Reward } \times \\
\text { formality }\end{array}$ & Wilks's $\Lambda=0.98, F(6,460)=0.98, P=.438$ & Competence $F(2,232)=1.03, P=.359$ \\
& & Character $F(1,232)=2.17, P=.123$ \\
\hline
\end{tabular}

Post hoc univariate tests for the reward main effect indicated that subjects rated the high reward value teacher higher in character and somewhat higher on competence (effect sizes were hand calculated using the formula recommended by Levine and Hullett [40] for $\eta^{2}$ ). Post-hoc univariate analyses of the formality main effect indicated significant main effects for competence, character, and caring. It was always the teacher in the high-formality clothing condition that received the highest credibility ratings. Post-hoc Tukey HSD tests on these means indicated that for all three dependent measures, the formal condition was significantly higher than the moderate condition, and the moderate condition never differed significantly from the casual condition. The formally dressed teachers were rated as significantly more caring and as having significantly more character than their casual counterparts. The means for competence, character, and perceived caring are visually displayed in Figures 2, 3, and 4 , respectively.

As a further test of hypotheses 1 and 2, a similar 2 (reward level) by 3 (clothing formality) MANOVA was run on the two attractiveness subscales and the homophily scale. Results of this analysis, found in Table 4, indicated no significant multivariate main effect for reward level. However, there was a significant multivariate main effect for clothing formality. As with the ratings of credibility, there was no reward level by clothing formality interaction. Posthoc univariate tests for the formality main effect indicated significant differences in ratings of physical attractiveness, but not social attractiveness or homophily. Tukey HSD tests indicated that the moderately dressed teachers were rated as significantly more physically attractive than the casually dressed teachers. However, the formally dressed teachers did not differ significantly from either of the other two clothing conditions. The means for social attractiveness, physical attractiveness, and homophily are visually represented in Figures 5, 6, and 7, respectively.

In general, the interaction between reward value and degree of expectancy violation in clothing formality that is predicted by EVT was not supported by these results. Rather, it appears that clothing formality operates independent of teacher reward value such that the more formal than

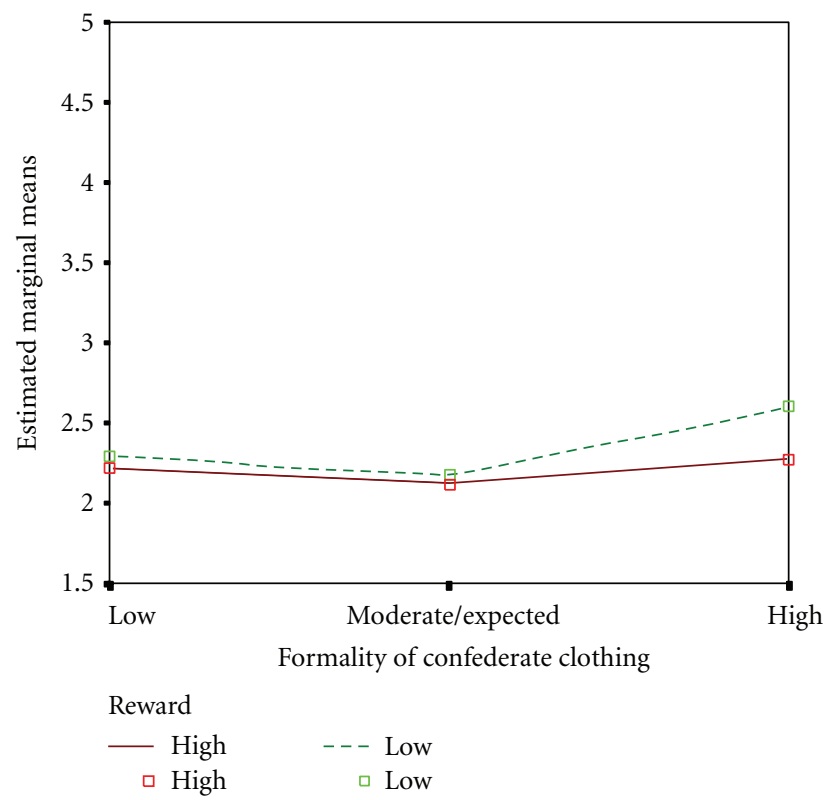

FIGURE 2: Effects of reward valence and formality on competence.

expected teacher was generally rated higher than the moderately or casually dressed teacher. This effect for formality of clothing was unquestionably more powerful than the effect for teacher reward level.

For the recall-dependent measure, hypothesis 1 predicted that under conditions of high reward, the best recall should occur in the formal or casual conditions. Hypothesis 2 predicted the exact opposite pattern for low-reward teachers: the moderately dressed teachers would be attended to most carefully, thus producing greater recall of information than those teachers who violated expectations by being more or less formal than expected. These hypotheses were tested with a 2 (reward) by 3 (clothing formality) ANOVA that treated recall accuracy as the dependent measure. This analysis indicated no significant main effect for reward level, $F(1,223)=3.09, P=.080$, although the pattern of means suggested slightly better recall from high-reward versus low-reward teachers when both were dressed moderately. 
TABLE 4: Multivariate analysis of variance for attractiveness and homophily ratings.

\begin{tabular}{|c|c|c|}
\hline $\begin{array}{l}\text { Independent } \\
\text { variable }\end{array}$ & Multivariate effect & Univariate effects \\
\hline Reward & Wilks's $\Lambda=0.99, F(3,219)=0.38, P=.766$ & $\begin{array}{l}\text { Soc. attrac. } F(1,221)=0.66, P=.416 \\
\text { Phys. attrac. } F(1,221)=1.03, P=.312 \\
\text { Homophily } F(1,221)=0.10, P=.749\end{array}$ \\
\hline Formality & Wilks's $\Lambda=0.92, F(6,438)=3.33, P=.003$ & $\begin{array}{l}\text { Soc. attrac. } F(2,221)=2.39, P=.094, \eta^{2}=.02 \\
\text { Phys. attrac. } F(2,221)=4.10, P=.018, \eta^{2}=.04 \\
\text { Homophily } F(2,221)=2.22, P=.111, \eta^{2}=.02\end{array}$ \\
\hline $\begin{array}{l}\text { Reward } \times \\
\text { formality }\end{array}$ & Wilks's $\Lambda=0.98, F(6,438)=0.81, P=.560$ & $\begin{array}{l}\text { Soc. attrac. } F(2,221)=1.82, P=.165 \\
\text { Phys. attrac. } F(2,221)=1.26, P=.285 \\
\text { Homophily } F(2,221)=0.64, P=.527\end{array}$ \\
\hline
\end{tabular}

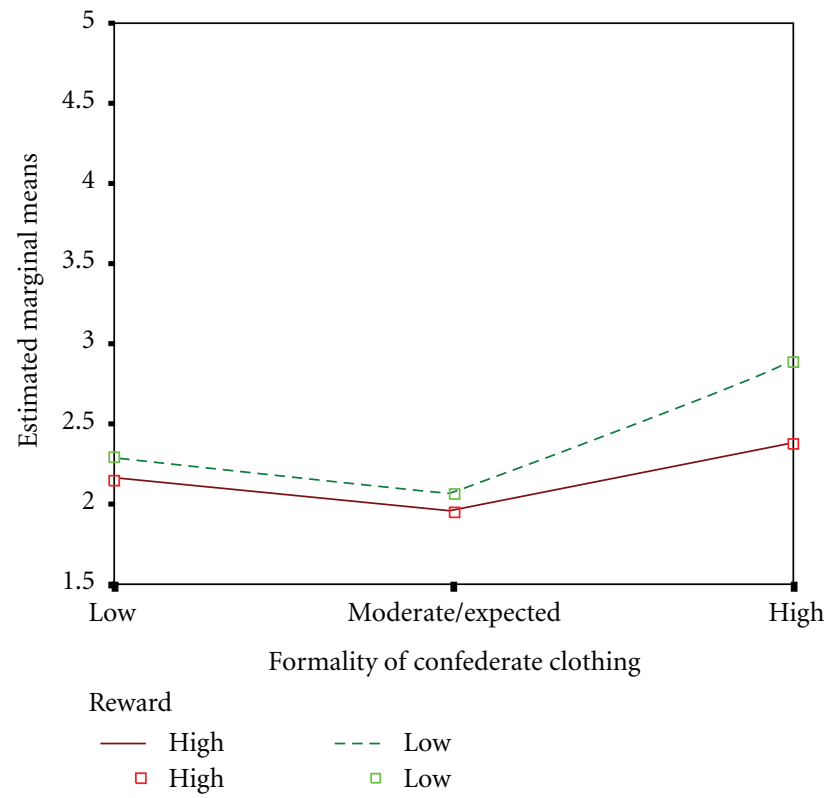

FIGURE 3: Effects of reward valence and formality on character.

However, there was a significant main effect for clothing formality, $F(2,223)=4.96, P=.008, \eta^{2}=.04$. There was no reward level by clothing formality interaction, $F(2,223)=2.30, P=.103$. Post-hoc analysis of the individual means with the Tukey HSD test indicated that the teacher who was dressed at a moderate level of formality produced significantly greater recall than the teacher dressed at the casual level. However, the formally dressed teachers did not differ significantly from the other two in terms of student recall. The means for recall accuracy are presented in Figure 8.

These results do not support the predictions of EVT as stated in these hypotheses. Once again, clothing formality appears to operate independent of teacher reward level. In this case, it was the teacher who wore the moderate attire who produced the greatest recall of lecture material.

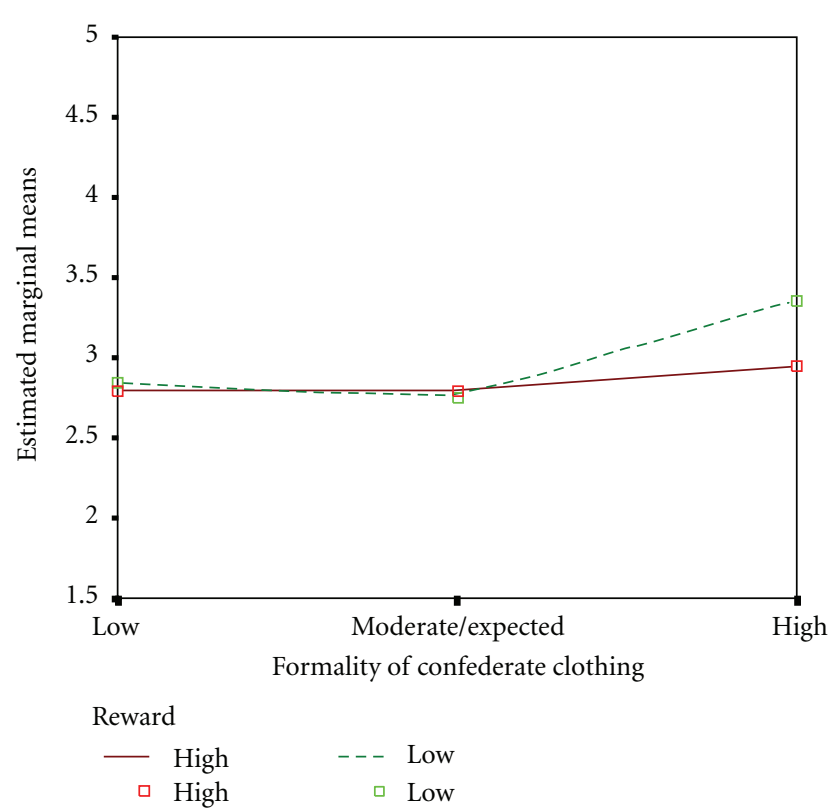

FIGURE 4: Effects of reward valence and formality on perceived caring.

\section{Discussion}

This study tested a core prediction from expectancy violations theory, namely, that high-reward communicators would produce the most favorable reactions and outcomes when their clothing behavior is deviant from the audience's expectations, and that low-reward communicators would produce the most favorable reactions and outcomes when their clothing behavior conforms to the audience's expectations. This hypothesis was tested in the context of an educational setting. The expected/unexpected nonverbal behavior was manipulated through the formality of college teachers' clothing. In general, the results are not supportive of the U-shaped pattern of outcomes that are expected for high reward communicators, and are only occasionally supportive 


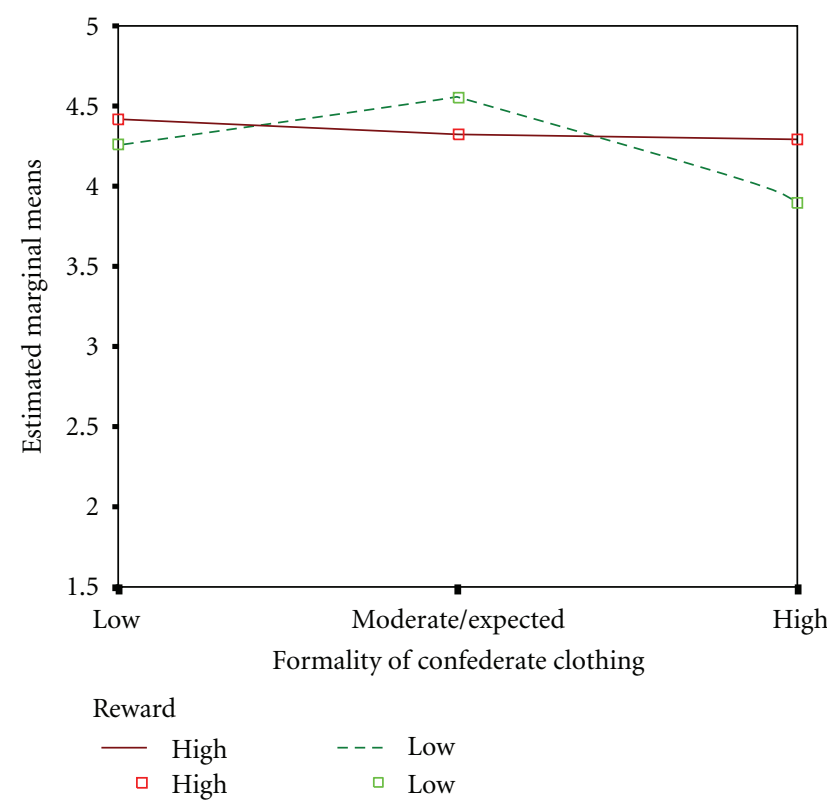

Figure 5: Effects of reward valence and formality on social attractiveness.

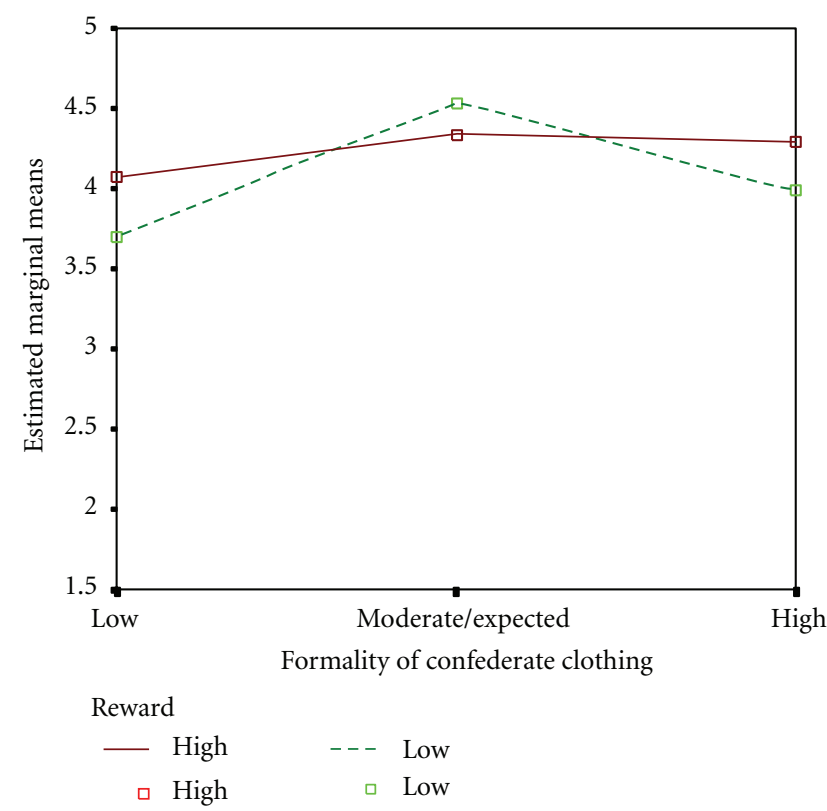

Figure 6: Effects of reward valence and formality on physical attractiveness.

of the inverted U-shaped pattern of results predicted for low-reward communicators. Rather, the results are more consistent with a "formality" main effect hypothesis whereby expectedly or beyond expectedly formal attire produced the most favorable attitudinal and cognitive outcomes from the student audiences, regardless of the reward value of the teacher. This is further bolstered by fact that the effect sizes for formality reveal it was the most influential variable, although the magnitude of these effects should still be considered small.

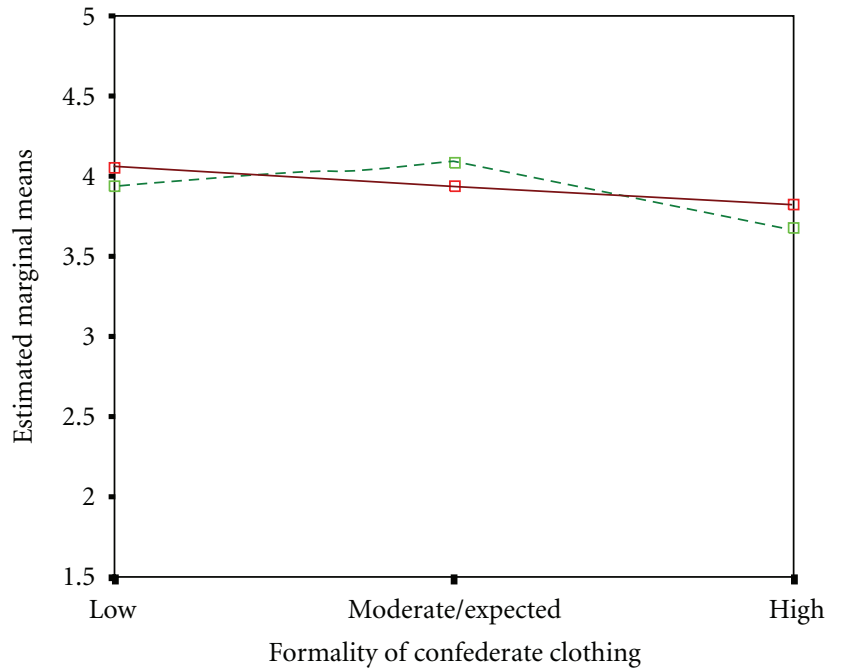

Reward

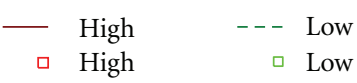

FIgURE 7: Effects of reward valence and formality on homophily.

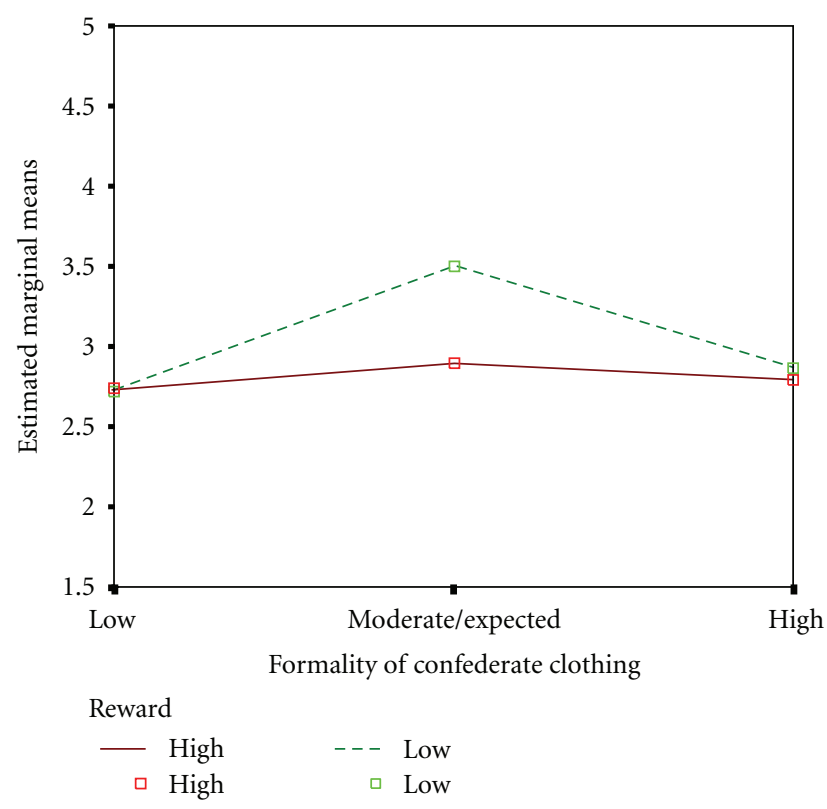

FIGURE 8: Effects of reward valence and formality on recall accuracy.

\section{Clothing and Teacher Credibility}

Results for teacher credibility ratings indicate that the teachers who wore the most formal attire consistently received the highest ratings of credibility from students, regardless of their reward valence. These results are consistent with numerous studies in the area of clothing and compliance gaining that consistently reveal a positive association between the formality or status conveyed through the clothing, and the success of compliance-gaining attempts [17, 19]. This is similar to the findings of Workman et al. [24] and Lightstone et al. [28] who found that formal clothing 
received the highest ratings of credibility and intelligence but the semiformal and informal clothing were not significantly different from each other. Results from this study suggest that the positive effects for formal clothing on perceptions of competence appear to be as achievable though moderately (i.e., expected) formal attire as through very formal (i.e., beyond expectation) attire, especially when the wearer otherwise has a high reward value to the audience.

\section{Clothing and Teacher Attractiveness}

The pattern of means for ratings of low reward value teachers' attractiveness, although not significantly different, were generally consistent with the predictions of EVT, in that those who conformed to audiences' expectations produced the most favorable outcomes. However, for the high reward value teachers, clothing formality had little effect on ratings of attractiveness. These distinctions between high and low reward value teachers are very tentative in that there was no reward value main effect for any of the attraction measures.

Collectively, teachers in the moderate and formal clothing conditions were rated as more physically attractive than the more casually dressed teacher, regardless of the reward value condition. As with credibility, more formal clothing may not improve outcomes relative to moderate formality, but casual clothing was clearly seen as less attractive than the other two styles.

A notable feature of the results on attractiveness is the lack of main effects for clothing formality on students' ratings of the teachers' social attractiveness or homophily. Given the generally casual clothing practices of American undergraduate students, it is surprising that students did not rate the more casually dressed teachers as particularly similar to the self. This suggests that students may not rely on the formality of a teacher's clothing when making judgments about similarity to the self. Perhaps other dimensions of clothing such as color schemes and stylishness, are more salient cues to homophily than formality.

Unlike the results from Butler and Roesel's [30] study, students in this study did not see casually dressed teachers as any more socially attractive than more formally dressed teachers. This may be due in part to business orientation of both the students and class that they were in. College business majors may not be as predisposed to find blatantly casual attire as socially attractive, compared to high school students such as those in Butler and Roesel's study, who may find the behavior to be desirably rebellious.

\section{Message Learning}

Students were expected to exhibit best recall of message content when the clothing of high-reward communicators was discrepant from expectation, and when the clothing of low-reward communicators conformed to expectation. However, this interaction between formality and reward value was not evident. Rather, it was the teacher who dressed at the moderate level who appeared to produce the best learning in the students when compared to those who wore unexpectedly casual attire. There was no significant difference between the moderate and formally dressed teachers. These results are explainable by considering the effects of distraction on message learning and attitude formation [41]. The moderate attire may be seen least salient and distracting to students, allowing them to focus largely on the information being presented rather than the unusual clothing of the teacher.

\section{Clothing Formality and Teacher Reward Value}

Expectancy violations theory predicts an interaction between communicator reward value and the extent to which communicators' behavior conforms to or violates expectation. Results from this study, however, indicate that reward value and violations of expectations (of clothing formality) operate independent of each other. One of the more consistent findings from this study was the lack of any effect for formality under conditions of high teacher reward. For virtually all dependent variables (e.g, credibility, attractiveness, and recall of message content) there was little discrimination among the different clothing styles, provided that the teacher was in the high-reward condition. It appears as if students overlook a teacher's clothing upon learning that the teacher will be an effective conduit to a high score on an upcoming exam. Once they saw this inherent value in the teacher, they did not seem to care what he or she was wearing when making judgments of his or her attractiveness and credibility. On the other hand, when the utility of the teacher was less apparent, the pattern of means suggested that students may have attended more carefully to his or her clothing when making these judgments. This suggest that a teacher's clothing will be a less consequential determinant of the impression that their students form, to the extent that they are otherwise perceived as having a high instrumental value.

\section{EVT and Teacher Clothing}

Some empirical tests of EVT have yielded conclusions that question the pervasiveness of the predicted interaction between communicator reward value and expected or unexpected nonverbal behavior for explaining outcomes and reactions from others. Burgoon [42, page 107] noted that "it appears that a U pattern may not be applicable to all communication consequences across all communication contexts" Shortly thereafter, in discussing the results of an investigation on nonverbal involvement behaviors, Burgoon and her colleagues argued that "consensual meanings attached to a violation may override any modified interpretations due to reward, in which case a social meanings model prevails. It therefore becomes an empirical question as to which types of nonverbal acts are subject to alternative interpretations, based on communicator characteristics, and which ones are not" [43, page 110$]$.

Expectancy violation theory may therefore have greater utility for explaining and predicting students' reactions to other teacher nonverbal behaviors such as eye contact, speech rate, and interpersonal distance. However, in the domain of clothing, a "social meanings model" (i.e., formal 
clothing is associated with a more credible teacher) appears to offer a better account of students' social perceptions. The lack of any reward value by clothing formality interactions in this investigation suggests that perhaps the importance of a cue that observers attribute to a source is useful explanatory mechanism for nonverbal acts that take the form of formal and informal clothing worn by teachers in the classroom. Clothing formality appears to have a certain meaning to students, and regardless of the reward value of the teacher, those who wear formal clothing tend to produce the greatest perceptions of credibility. However, the meanings of formal attire appear somewhat less positive in terms of what students perceive to be attractive, as the moderate, or expectedly formal, attire was associated with the more favorable judgments of attractiveness. These results highlight scope conditions for behaviors and contexts in which the predictions of EVT may not be relevant.

It should be kept in mind that, as with most academic studies, this experiment was conducted in a particular academic institution with its own particular norms and practices which may not hold true in all academic contexts. However, if the students in this study are typical, there are some lessons that may be learned from this research. In general, the results of this study support the recommendation made Lukavsky et al. [27] that teachers should strive for a moderate clothing style. Students pay more attention to clothing as a cue when the teacher's inherent value is not apparent. In addition, students who are not distracted by their teacher's appearance recall more of what is said and find their teacher more credible and attractive. Although some small gains are made by erring on the side of overly formal clothing, the advantages are minimal. By erring on the side of overly informal clothing however, a teacher risks greater losses in credibility and attractiveness.

\section{Acknowledgment}

The authors would like to thank Drs. Michael Peters and Stacy Wolski for their assistance with the project.

\section{References}

[1] J. K. Burgoon, "A communication model of personal space violations: explication and an initial test," Human Communication Research, vol. 4, pp. 129-142, 1978.

[2] J. K. Burgoon, "Interpersonal expectations, expectancy violations, and emotional communication," Journal of Language and Social Psychology, vol. 12, pp. 30-48, 1993.

[3] J. K. Burgoon, "Cross-cultural and intercultural applications of expectancy violations theory," in Intercultural Communication Theory, R. L. Wiseman, Ed., vol. 19, pp. 194-214, Sage, Thousand Oaks, Calif, USA, 1995.

[4] J. K. Burgoon, "Applying a comparative approach to nonverbal expectancy violations theory," in Comparatively Speaking, J. Blumler, K. E. Rosengren, and J. M. McLeod, Eds., pp. 53-69, Sage, Newbury Park, Calif, USA, 1992.

[5] J. K. Burgoon and J. L. Hale, "Nonverbal expectancy violations: model elaboration and application to immediacy behaviors," Communication Monographs, vol. 55, pp. 58-79, 1988.
[6] J. K. Burgoon and S. B. Jones, "Toward a theory of personal space expectations and their violations," Human Communication Research, vol. 2, pp. 131-146, 1976.

[7] K. Floyd, A. Ramirez, and J. K. Burgoon, "Expectancy violations theory," in The Nonverbal Communication Reader: Classic and Contemporary Readings, L. K. Guerrero, J. A. DeVito, and M. L. Hecht, Eds., pp. 437-444, Prospect Heights, Waveland, Ill, USA, 1999.

[8] J. K. Burgoon, D. B. Buller, and G. W. Woodall, Nonverbal Communication: The Unspoken Dialogue, McGraw-Hill, New York, NY, USA, 1996.

[9] J. K. Burgoon and L. Aho, "Three field experiments on the effects of violations of conversational distance," Communication Monographs, vol. 49, pp. 71-88, 1982.

[10] D. U. Behling and E. A. Williams, "Influence of dress on perceptions of intelligence and expectations of scholastic achievement," Clothing and Textiles Research Journal, vol. 9, no. 4, pp. 1-7, 1991.

[11] L. Bickman, "The effect of social status on the honesty of others," Journal of Social Psychology, vol. 85, pp. 87-92, 1971.

[12] A. L. Chaiken, V. J. Derlega, J. Yoder, and D. Phillips, "The effects of appearance on compliance," Journal of Social Psychology, vol. 92, pp. 199-200, 1974.

[13] H. Giles and W. Chavasse, "Communication length as a function of dress style and social status," Perceptual and Motor Skills, vol. 40, pp. 961-962, 1975.

[14] S. Lambert, "Reactions to a stranger as a function of style of dress," Perceptual and Motor Skills, vol. 35, pp. 711-712, 1972.

[15] M. Lefkowitz, R. R. Blake, and J. S. Mouton, "Status factors in pedestrian violation of traffic signals," Journal of Abnormal and Social Psychology, vol. 51, no. 3, pp. 704-706, 1955.

[16] B. J. Bushman, "Perceived symbols of authority and their influence on compliance," Journal of Applied Social Psychology, vol. 14, pp. 501-508, 1984.

[17] B. J. Bushman, "The effects of apparel on compliance: a field experiment with a female authority figure," Personality and Social Psychology Bulletin, vol. 14, pp. 459-467, 1988.

[18] L. Bickman, "The social power of a uniform," Journal of Applied Social Psychology, vol. 4, pp. 47-61, 1974.

[19] C. Segrin, "The effects of nonverbal behavior on outcomes of compliance gaining attempts," Communication Studies, vol. 44, pp. 169-187, 1974.

[20] E. M. Fitch, Appropriateness and promotability of clothing behavior of women teachers, Ph.D. thesis, Yeshiva University, New York, NY, USA, 1984.

[21] R. E. Bassett, "Effects of source attire on judgements of credibility," Central States Speech Journal, vol. 30, pp. 282-285, 1984.

[22] D. Carr, T. Davies, and A. Lavin, "The effect of business faculty attire on student perceptions of quality of instruction and program quality," College Student Journal, vol. 43, no. 1, pp. 45-55, 2009.

[23] K. D. Roach, "Effects of graduate teaching assistant attire on student learning, misbehaviors, and ratings of instruction," Communication Quarterly, vol. 45, no. 3, pp. 125-141, 1997.

[24] J. E. Workman, K. K. Johnson, and B. Hadeler, "The influence of clothing on students' interpretative and extended inferences about a teaching assistant," College Student Journal, vol. 27, no. 1, pp. 119-128, 1993.

[25] S. Butler and K. Roesel, "Research note: the influence of dress on students' perceptions of teacher characteristics," Clothing and Textiles Research Journal, vol. 7, no. 3, pp. 57-59, 1989.

[26] M. A. Davis, Age and dress of professors: influence on students' first impressions of teaching effectiveness, Ph.D. thesis, Virginia 
Polytechnic Institute and State University, Blacksburg, Va, USA, 1992.

[27] J. Lukavsky, S. Butler, and A. J. Harden, "Perceptions of an instructor: dress and students' characteristics," Perceptual and Motor Skills, vol. 81, no. 1, pp. 231-240, 1995.

[28] K. Lightstone, R. Francis, and L. Kocum, "University faculty style of dress and students' perception of instructor credibility," International Journal of Business and Social Science, vol. 2, no. 15 , pp. 15-22, 2011.

[29] S. J. Sweat and M. A. Zentner, "Female appearance presentation: gender differences in social attribution and situational choice," Home Economics Research Journal, vol. 14, no. 2, pp. 175-186, 1985.

[30] S. Butler and K. Roesel, "Students' perceptions of male teachers: effects of teachers' dress and students' characteristics," Perceptual and Motor Skills, vol. 73, no. 3, pp. 943-951, 1991.

[31] M. L. Damhorst, "In search of a common thread: classification of information communicated through dress," Clothing and Textiles Research Journal, vol. 8, no. 2, pp. 1-12, 1990.

[32] T. L. Morris, J. Gorham, S. H. Cohen, and D. Huffman, "Fashion in the classroom: effects of attire on student perceptions of instructors in college classes," Communication Education, vol. 45, no. 2, pp. 135-148, 1996.

[33] J. Gorham, S. H. Cohen, and T. L. Morris, "Fashion in the classroom II: instructor immediacy and attire," Communication Research Reports, vol. 14, no. 1, pp. 11-23, 1997.

[34] J. C. McCroskey, "Scales for the measurement of ethos," Speech Monographs, vol. 33, no. 1, pp. 65-72, 1966.

[35] J. J. Teven and J. C. McCroskey, "The relationship of perceived teacher caring with student learning and teacher evaluation," Communication Education, vol. 46, no. 1, pp. 1-9, 1997.

[36] J. C. McCroskey and T. A. McCain, "The measurement of interpersonal attraction," Speech Monographs, vol. 41, pp. 261266, 1974.

[37] J. C. McCroskey, V. P. Richmond, and J. A. Daly, "The development of a measure of perceived homophily in interpersonal communication," Human Communication Research, vol. 1, pp. 323-332, 1975.

[38] D. Byrne, The Attraction Paradigm, Academic Press, New York, NY, USA, 1971.

[39] M. Sunnafrank, "Interpersonal attraction and attitude similarity: a communication-based assessment," Communication Yearbook, vol. 14, pp. 451-483, 1991.

[40] T. R. Levine and C. R. Hullett, "Eta squared, partial eta squared, and misreporting of effect size in communication research," Human Communication Research, vol. 28, no. 4, pp. 612-625, 2002.

[41] R. E. Petty, G. L. Wells, and T. C. Brock, "Distraction can enhance or reduce yielding to propaganda: thought disruption versus effort justification," Journal of Personality and Social Psychology, vol. 34, no. 5, pp. 874-888, 1976.

[42] J. K. Burgoon, "Nonverbal violations of expectations," in Nonverbal Interaction, J. M. Wiemann and R. P. Harrison, Eds., pp. 77-112, Sage, Beverly Hills, Calif, USA, 1983.

[43] J. K. Burgoon, D. A. Newton, J. B. Walther, and E. J. Baesler, "Nonverbal expectancy violations and conversational involvement," Journal of Nonverbal Behavior, vol. 13, no. 2, pp. 97-120, 1989. 

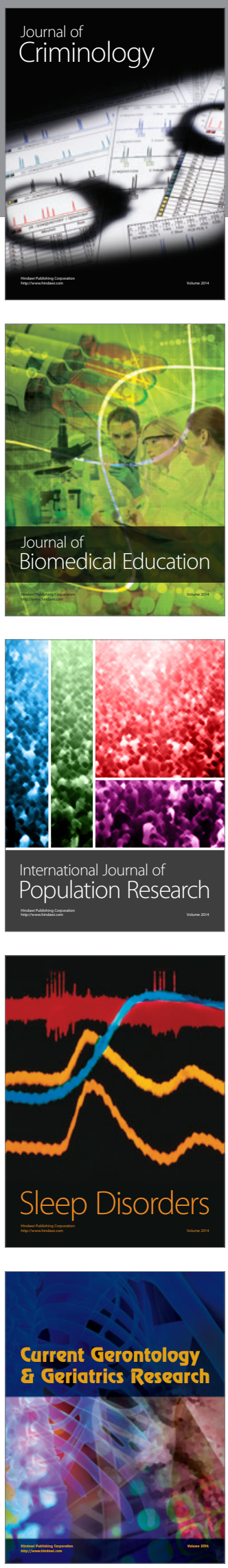
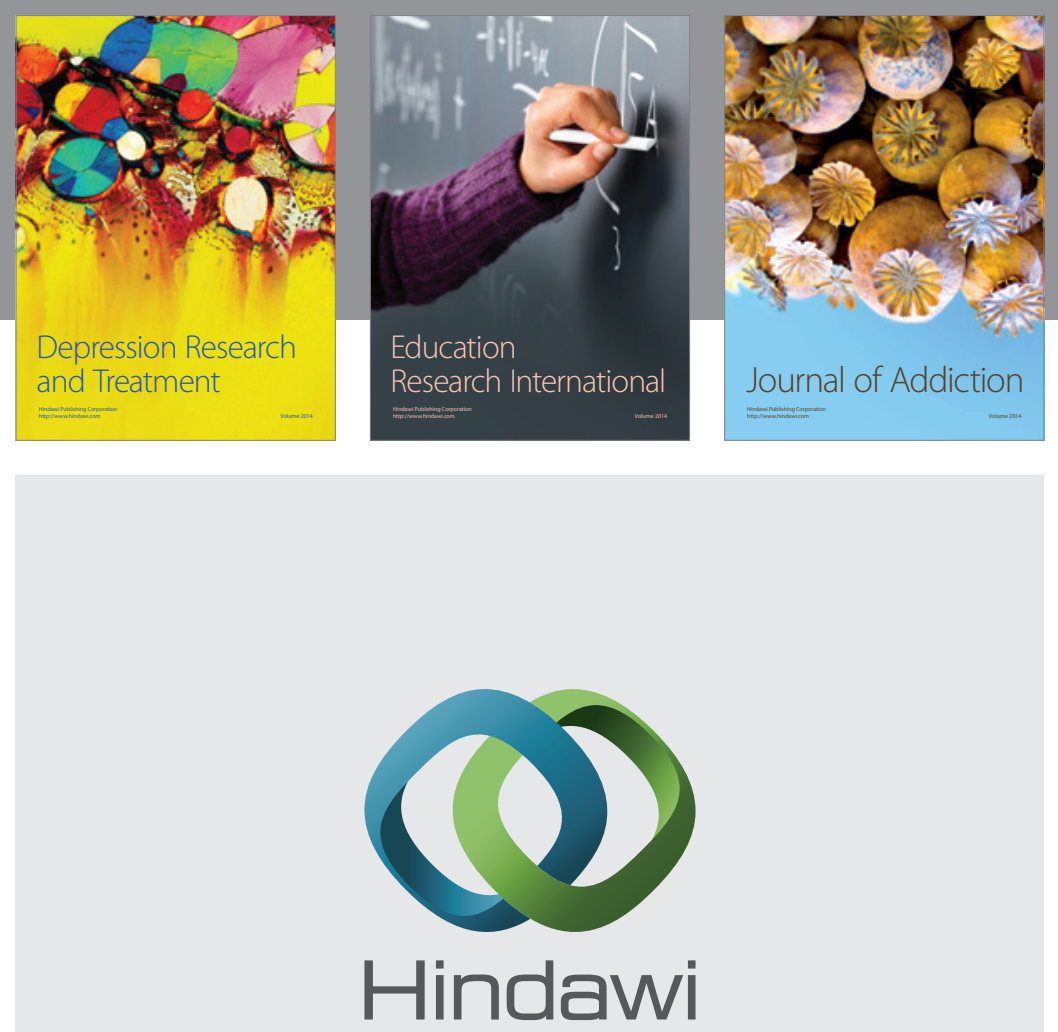

Submit your manuscripts at

http://www.hindawi.com

Child Development Research
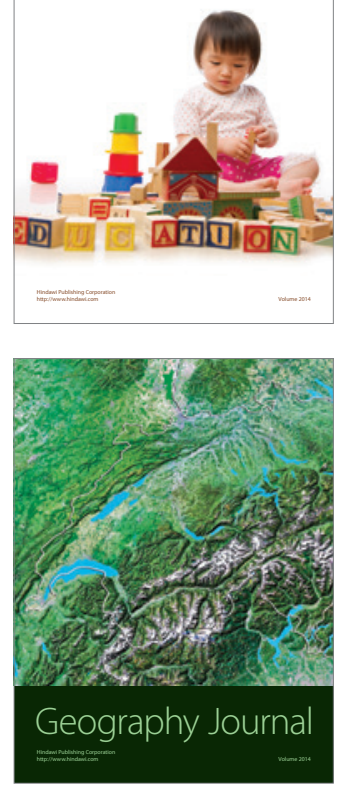

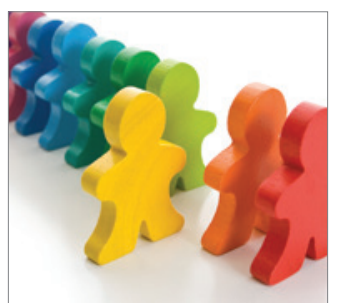

Autism

Research and Treatment
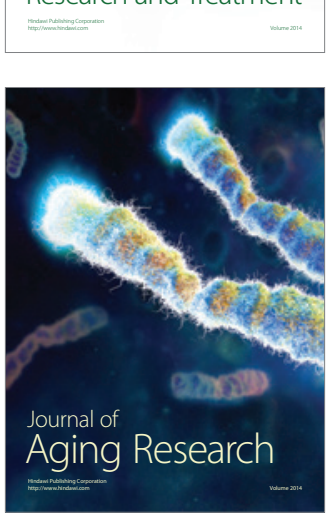
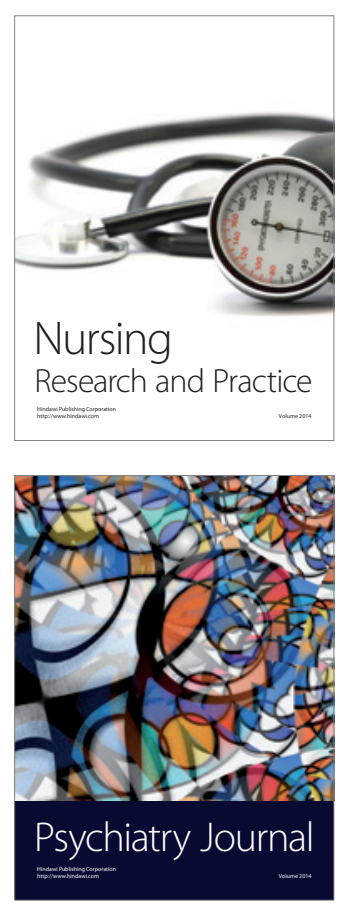
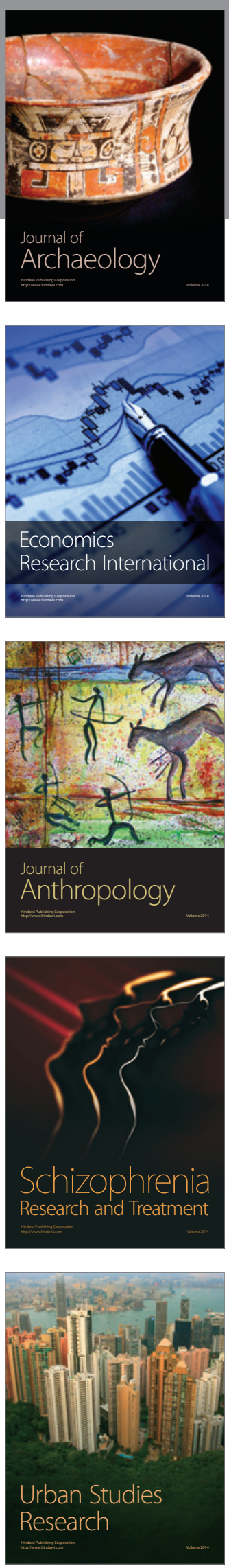